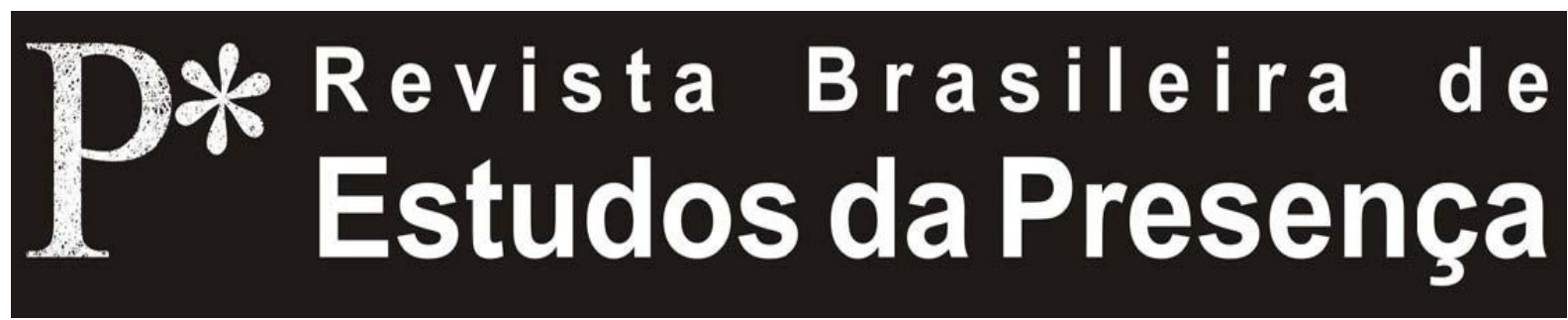

DOI - http://dx.doi.org/10.1590/2237-266025711

ISSN 2237-2660

\title{
Gesto Arquétipo e Gesto Cotidiano: um binômio fundamental na teoria delsartiana
}

Elena Randi

Università degli Studi di Padova - Padova, Itália

RESUMO - Gesto Arquétipo e Gesto Cotidiano: um binômio fundamental na teoria delsartiana - Este texto apresenta o sistema de François Delsarte a partir de um ponto de vista histórico-explorativo, evidenciando alguns aspectos particulares do trabalho do mestre francês e da interpretação do seu trabalho pelos seus principais discípulos. O artigo descreve o estatuto do corpo e sua importância no sistema delsartiano, mostrando as noções de gesto arquétipo e gesto cotidiano como fundamentos desse sistema. Com efeito, o texto aponta tanto dados históricos extraídos dos arquivos de Delsarte, quanto argumentos que questionam a autoria de um sistema de exercícios atribuído a Delsarte, que, segundo o texto, poderiam ter sido engendrados por seus discípulos.

Palavras-chave: François Delsarte. Gesto. Artes Cênicas. História da Dança. História do Teatro.

ABSTRACT - Archetypal Gesture and Everyday Gesture: a fundamental binomial in Delsartean theory - This text presents François Delsarte's system from a historical-exploratory viewpoint, focusing on some particular aspects of the work of the French master and the interpretation of his work by some of his main disciples. The article describes the status of the body and its importance in the Delsarte system, taking the notions of archetypal gesture and everyday gesture as the bases of this system. Indeed, the text highlights both historical facts obtained from the Delsarte archive, and arguments questioning the authorship of exercises attributed to Delsarte, which, according to the text, may have been created by his students.

Keywords: François Delsarte. Gesture. Performing Arts. History of Dance. History of Theatre.

RÉSUMÉ - Geste Archétype et Geste Quotidien: un binôme fondamental dans la théorie delsartienne - Ce texte présente le système de François Delsarte à partir d'un point de vue historico-explorateur, mettant en évidence quelques aspects particuliers du travail de ce maître français et donnant un aperçu de l'interprétation qu'en ont faite ses principaux disciples. L'article décrit le statut du corps et son importance dans le système delsartien. Il montre que les notions de geste quotidien et de geste archétype constituent les fondations de ce système. En effet, ce texte apporte aussi bien des données historiques extraites des archives de Delsarte que des arguments mettant en cause la paternité d'un système d'exercices attribué normalement à Delsarte mais qui, d'après le texte, pourrait avoir été conçu par ses disciples.

Mots-clés: François Delsarte. Geste. Arts du Spectacle. Histoire de la Danse. Histoire du Théâtre. 
Talvez em primeiro lugar seja apropriado reiterar alguns pontos-chave. No pensamento de François Delsarte o cosmos tem configuração geométrica, de acordo com uma antiga tradição que começou com Timeu de Platão e, antes disso, com o Livro da Sabedoria, segundo o qual o Artifex havia construí-do o mundo baseado em peso, número e tamanho. Delsarte ilustra nos mínimos detalhes a geometria macrocósmica, que se reflete em proporções reduzidas no microcosmos. A obstinação com a qual ele apresenta isso tem algo de maníaco e talvez constitua o ponto mais árido do seu pensamento. Sua opinião é que toda a criação reitera na sua estrutura secreta o modelo trinitário. Sem me deter sobre as pessoas divinas e sobre a esfera angelical, passo diretamente para a tripartição sobre o homem. Três, de acordo com Delsarte, são as principais áreas em que é subdividido o homem interior: a vida, para não ser confundida com o corpo do qual é absolutamente distinta, é a força por intermédio da qual as coisas são impressas em nós através do canal dos sentidos; o espírito é a faculdade que está ligada ao mental, ao número e à abstração; a alma é a área do sentimento e dos afetos. Esses são termos que, no pensamento delsartiano, são inseparáveis e coessenciais.

A cada parte dos três mundos, relativo ao homem interior, corresponde uma modalidade de expressão: a vida é manifestada de forma mais imediata pela phonè, o espírito pela palavra e a alma pelo gesto.

Se geométrica é a estrutura do cosmos, geométrica deve ser a arte ideal, como reflexo do supramundano, lugar no qual se revela a ordem na qual o universo foi construído. Nele, devem estar coexistentes a voz e também o canto e, por extensão, a música, a fala, e, portanto, a poesia, o gesto e, também, a mímica (ou a dança), num padrão que lembra, embora com alguma diferença significativa, o padrão wagneriano.

Ao atuar como um elo de ligação entre a vida e o espírito, a alma, ou seja, o elemento emocional é, segundo um módulo da mística medieval romanticamente revisitado, a mais alta esfera da tríade relativa ao homem interior, é o polo capaz de colocar em relação os opostos. Daqui resulta que o gesto, que da alma é o mais primário modo de expressão, está no 
degrau mais alto de uma hierarquia ideal das linguagens, e a mímica, que do gesto é a forma artística, está situada em um nível superior em relação à música e à poesia (Randi, 1996).

Uma referência útil para entender a origem que tem a ideia da supremacia do movimento corpóreo com relação à fala e à voz é a situação espetacular de Paris no tempo no qual Delsarte viveu. Naquela época, contava-se com um número significativo de salas de espetáculos: por volta de 20 a 40, no período de 1820-1870. Detenhamo-nos apenas sobre o período de formação de Delsarte, considerando que cada teatro tinha uma licença para representar apenas um ou dois gêneros. As únicas salas propriamente destinadas ao teatro falado eram a Comédie-Française e o Odéon; a Porte-Saint-Martin e um par de outros teatros tinham a permissão de preparar dramas juntamente com diferentes tipos de espetáculo. Em todos os demais, o peso da visualidade, que consiste em cenografia, figurinos, iluminação, pantomima, acrobacia, era predominante em relação ao aspecto verbal, no sentido de que a palavra/fala estava ausente (como no balé e em certos gêneros pantomímicos) ou era de pouco valor literário. Em alguns casos, como no melodrama, a música tinha uma posição dominante (de qualquer modo, não a palavra), mas de qualquer forma continua a ser fundamental o aparato visual. E, além disso, mesmo quando o texto tem grande importância, como na Comédie, o elemento visual constitui uma parte considerável na economia da representação. Em todos os teatros dos bulevares, os atores cultivavam cuidadosamente a sua preparação mímica e acrobática. Não pode ser muito difícil de entender como, nessa situação, Delsarte possa ter elaborado um pensamento no qual a centralidade do gesto se torna um aspecto basilar.

As suas ideias sobre o movimento se baseiam mesmo em sugestões teóricas. Uma primeira fonte de referência importante sobre o assunto é constituída por São Tomás de Aquino, da qual Delsarte enfatiza, sobretudo, um aspecto da antropologia, interpretado segundo coordenadas modernas: que o corpo e a alma estão perfeitamente correlacionados, não são duas entidades separadas nem separáveis; em várias ocasiões Delsarte cita uma frase de São Tomás, tornando-a sua (e reportando-a 
frequentemente à memória, com uma mínima variante): “A natureza da alma é ser a forma do corpo" (D. C. 12. 86, p. 75; [Porte, 1992, p. 104]) $)^{1}$, onde o termo "alma" é entendido não como até aqui foi explicado, mas como a esfera interna humana em sua totalidade, que compreende a vida, a alma e o espírito.

A ideia do gesto como uma linguagem capaz de expressar com eficácia particular o sentimento e o affectus encontra-se, embora por vezes apenas em sugestões, em vários autores um pouco anteriores a Delsarte ou mais ou menos seus contemporâneos: em filósofos como Diderot ou Schleiermacher, em poetas como Vacquerie ou Lamartine, em coreógrafos como Noverre, em atores como Talma ou Morrocchesi.

Uma fonte mais direta de referência sobre a relação entre a psique e a expressão corporal é constituída pela idéologie, uma filosofia de pensamento presente na França entre o final do século XVIII e as primeiras décadas do século seguinte. Por toda a sua vida Delsarte empenhou-se em uma série de investigações de argumento puramente idéologique: a já mencionada relação entre os sinais de expressão e a atividade interna, a influência do hábito na linguagem corporal e nas funções intelectuais, o exame das relações entre a moral e a physique.

Além dos temas de exame, Delsarte compartilha com a idéologie ortodoxa (Cabanis e Destutt de Tracy, especialmente) a ideia da correlação irredutível entre corpo e psique, que são, por Cabanis, um unicum inseparável. Mas Cabanis, assim como Tracy, acredita que entre eles há uma unidade ontológica, no sentido que a moral é reduzida em uma entidade orgânica, corporal. $\mathrm{O}$ intelecto e os sentimentos são organização material, matéria; mesmo as dinâmicas emocionais mais espirituais, como o amor e a alegria, são traçadas em mecanismos fisiológicos, dissolvendo-se nos mesmos.

Nada disso aparece em Delsarte, razão pela qual, ao referir-se aos idéologues, o faz apenas em termos muito hostis (D. C. 12. 86, p. 116; [Porte, 1992, p. 120]2; D. C. 11. 40, p. 543; Traité..., 1870, p. 251). Quanto à natureza do intérieur, de fato, ele se alinha a posições semelhantes as de Degérando ou de Maine Biran, os quais, depois de terem servido entre 
as fileiras dos idéologues, afastam-se das teses da escola de origem, embora mantendo o objeto de investigação. Da idéologie, acima de tudo, perdem a visão materialista: o intérieur torna-se força intangível, diferenciando-se ontologicamente da physique, com a qual ainda mantém uma intensa correspondência. Essa visão os leva a uma série de aberturas para novas questões.

Um ponto em particular da filosofia biraniana parece oferecer tema de meditação para Delsarte: se por um lado a sensibilidade, ou seja, a faculdade graças a qual se penetra em nós a realidade exterior, é passiva, do outro o Eu intérieur observa Biran - é um instrumento ativo de conhecimento. Para reconhecer uma sensação, transformando-a em uma percepção ou uma ideia e não abandoná-la ao inconsciente, é necessária a intervenção de uma força interior ativa.

Delsarte acolhe, então, de um lado, a ideia da correspondência entre intus e foris e, de outro, a revisão, oferecida pela heresia idéologique, da psique como força imaterial e da presença em nós de dois polos, um passivo e inconsciente, e outro dinâmico e consciente. Talvez a partir dessa sugestão Delsarte também tenha começado a observar a existência de movimentos do corpo conscientes e de outros involuntários, a estudar sua relação com a esfera interior e a examinar as relações entre o gesto governado e aquele não gerado racionalmente.

As sugestões de Biran parecem combinar-se no pensamento de Delsarte com aquelas oferecidas pelas controvérsias do final do século XVIII entre fisiognomonia e patognomonia. Em um primeiro momento eu havia pensado no mestre francês como um proselita de Johann Caspar Lavater, convencido da possibilidade de deduzir aspectos específicos da psicologia do indivíduo com base à configuração (comprimento, largura, espessura etc.) de um determinado órgão. Um julgamento lisonjeiro em relação a Lavater, expresso por Delsarte no juvenil Méthode Philosophique du Chant, parecia reforçar essa hipótese (Delsarte, 1833 apud Porte, 1992, p. 153).

Mas dar crédito a fisiognomonia colocou-me diante de um impasse: dizer que a estrutura anatômica do indivíduo, estática por definição, é indicativo de um determinado caráter, significa limitar as possibilidades interpretativas do ator aos 
personagens dotados de uma partitura psicológica semelhante a sua própria. $\mathrm{O}$ ator que interpreta Hamlet, por exemplo, só poderia ter a constituição física de ser falso e ambíguo, admitindo que o acento interpretativo seja baseado sobre tais coordenadas; o Pai de família, a de um homem moralmente nobre; o Mal, a constelação de sinais externos que, dada a estreita relação entre physis e psyché, a natureza atribui a tal tipo de caráter. Isso, porém, resultaria em uma consequência fatal: a inutilidade da técnica atoral definida pelo mesmo Delsarte. Como, de fato, é possível conciliar os fundamentos da fisiognomonia com um método atoral - como o delsartiano - cujo objetivo final está em superar a individualidade do intérprete? A ideia de uma necessária correspondência entre a psique e o tamanho estático do corpo é de fato incompatível com o princípio de passar por cima da própria personalidade a fim de entrar na pele de outro.

Se, na idade jovem, quando ainda não definiu o seu próprio método, Delsarte se desviou em favor de Lavater, ao longo do tempo deve ter modificado a sua própria visão. Em apoio a essa tese, estão algumas declarações da maturidade:

\begin{abstract}
O homem leva consigo a marca de três modelos distintos: o modelo estável ou constitucional, ou essencial, que é o modelo de nascença; o modelo habitual, adquirido sob a influência dos movimentos; o modelo passional ou passageiro, produzido pelas paixões que modificam temporariamente as formas. Os três modelos nos dão organicamente duas fontes de estudo: as formas e os movimentos. As formas nos revelam o valor íntimo do homem, as disposições que ele traz consigo ao nascer. Os movimentos nos revelam seus hábitos, seu estado particular, numa só palavra, seu valor relacional. [...] A forma nos ensina o que o homem pode ser, mas ela não nos ensina quem ele é. É a segunda fonte de nosso estudo, o gesto, que nos permite conhecer o estado atual de seu valor ${ }^{4}$ (D. C. 1.24 .5 , c. $\left.5 r-v\right)^{5}$.
\end{abstract}

A frase que mais conta é: "A forma nos ensina o que o homem pode ser, mas ela não nos ensina quem ele é6". $\mathrm{O}$ significado atribuído a tal afirmação é indicado logo depois: "É a segunda fonte de nosso estudo, o gesto, que nos permite conhecer o estado atual de seu valor" ". Em outras palavras, a 
constituição (a forme) do indivíduo mostra o homem potencial, os traços dinâmicos (o geste) indicam o indivíduo em ato, o seu état actuel, estado que pode ser totalmente diferente daquele estável ou constitucional ${ }^{8}$. Trata-se de uma distinção importante no plano teatral, porque ao ator é reconhecida a possibilidade, tão elevada quanto forem desenvolvidas as suas habilidades técnicas, de representar qualquer tipo de personagem.

Um fragmento relatado por Alain Porte, no qual as doutrinas de Lavater são chamadas de "puérilités", confirma o destacamento de Delsarte da visão lavateriana. O trecho de qualquer forma deve ser utilizado com a devida cautela, uma vez que Porte não especifica a fonte e, portanto, não é possível verificar a sua confiabilidade (Porte, 1992, p. 261).

$\mathrm{Na}$ maturidade, Delsarte parece misturar algumas das teses da fisiognomonia (a presença de uma chave universal de leitura do corpo) com outras da patognomonia (é a dinâmica do corpo a ser portadora dos significados interiores), modificando o resultado de ambas, e o faz aparentemente retomando uma sugestão contida nas engeliane Ideen zu einer Mimik (a tradução francesa das Ideen remonta a 1794: Idées sur le geste et l'action théâtrale, Paris, Jansen) ${ }^{9}$, sugestão traçada anos mais tarde de forma muito mais definida, central e aprofundada no pensamento balzaquiano, em particular na Théorie de la démarche $(1833)^{10}$. Refiro-me à tese de Delsarte segundo a qual no mundo das Origens existiria uma gestualidade (o termo é usado tanto no sentido estrito quanto como figura fonética) caracterizada por uma relação não mediada com a psique, uma linguagem universalmente conhecida e utilizada por todos, dotada de um caráter de verdade e de beleza. Mas, de acordo com uma concepção neoplatônica, também se acredita que no homem da modernidade ela está sepultada embaixo de um amontoado de sinais corruptos, em um momento pela intenção deliberada de mentir, e em um outro pelos hábitos incorretos adquiridos ao longo do tempo pelo indivíduo ou pela espécie. Podemos ler alguns trechos: 
A humanidade está estropiada, a beleza só existe em fragmentos, ela não se encontra em lugar nenhum nessa terra. Os arquétipos não podem ser encontrados, eles estão no intelecto e não na natureza. A beleza não existe em lugar nenhum, é preciso, consequentemente, que ela seja constituída pelo artista, por intermédio de um trabalho sintético (D. C. 12. 86, p. 18) ${ }^{11}$.

Ou:

Examinemos novamente o homem no que constitui essencialmente seu ser. Eu quero evocar as três potências para as quais Deus o fez à sua imagem [...]. O que me espanta, é a dissonância na qual elas se encontram. É o estado de desigualdade no qual elas entraram ${ }^{12}$ (D. C. 1. 26b. 10, c. 8; [Porte, 1992, p. 240]) $)^{13}$.

Ou ainda:

O homem traz consigo os traços inegáveis de uma grandeza extraordinária, pois ele não pode ter saído mutilado dessa maneira das mãos de seu criador e Deus não pôde mutilar sua obra estropiando assim sua semelhança [...]. Pode o homem ter saído assim, estropiado, das mãos de seu criador? Deus não fez o suficiente em sua obra predileta, ou então ele quis mutilar sua semelhança desde o berço da criação? Se fosse assim, Deus seria não somente um operário desordenado, mas também o mais duro, o mais injusto e cruel dos seres (D. C. 1. 26b. 10, cc. 8-9; [Porte, 1992, p. 240]) $)^{14}$.

Como de fato pensam os gnósticos, mas não Delsarte, que continua: "Tudo isso é inadmissível. No entanto, o homem traz consigo as características inegáveis de uma grandeza extraordinária" (D. C. 1. 26b. 10, cc. 8-9; [Porte, 1992, p. 240])15.

Para confirmar a presença somente fragmentária da verdade no gesto cotidiano, pode-se ler algumas páginas escritas pelo mestre francês relativas aos exemplos de movimentos feitos no espaço do real. Por exemplo:

Quando um homem lhe diz, de maneira interjetiva 'Eu amo, eu sofro, eu estou encantado, etc.', não acredite em nada se seu ombro permaneceu numa atitude normal [...]. Não acredite em nada, ele está mentindo! Seu ombro invalida sua palavra. Essa forma negativa traiu seu pensamento ${ }^{16}$ (D. C. 1. OS 36c. 2, c. 18 Chapitre VI; [Porte, 1992, p. 85] $)^{17}$. 
No caso específico, as palavras enganam, mas o ombro não mente. Cuidado, porém: durante o mesmo argumento, Delsarte acrescenta: "Não acredite em nada, seja qual for a expressão que adota o seu rosto (D. C. 1. OS 36c. 2, p. 18 Chapitre VI; [Porte, 1992, p. 85] $)^{18}$.

Isso quer dizer, enquanto o ombro é sincero na medida em que expressa o não-amor, a dinâmica do rosto consegue mentir perfeitamente, uma observação que demonstra que, pelo menos, certas partes do corpo (neste caso específico, o rosto) podem expressar um sentimento diferente daquele experimentado. Um outro exemplo:

Se alguém quer expressar a surpresa e se essa surpresa
não for precedida de um tremor na pálpebra, vocês po-
dem estar certos de que a surpresa é simulada. Se estou
esperando uma pessoa e finjo me emocionar quando a
vejo, vocês podem dizer 'é falso porque não houve tre-
mor no olhar' (D. C. 12. 86, p. 174)

Delsarte chama "extérieurs" os gestos não correspondentes à dinâmica interior e os atribui um juízo negativo, ou chama-lhes "gestes d'acteur" (D. C. 12. 86, p. 140) ${ }^{20}$ (não feitos por um ator, mas d'acteur (teatrais), ou seja, mentiras).

Apesar da falsidade geral do gesto, em cada um de nós se conservaria sempre, porém, pelo menos um particular, mesmo que pequeno, no qual transparece genuinamente a alma (um leve enrugar-se da testa, a voz que vibra, a contração de certo músculo). Haveria sempre, em outras palavras, um microgesto, um detalhe revelador da linguagem arquetípica, um indício da vida subterrânea que brilha sem o nosso conhecimento também no corpo mais protegido. Podemos dizer, portanto, que o vocabulário do corpo muda com o variar da história, mas, também, que entre os seus desdobramentos é possível descobrir os traços de um idioma universal que só nos primeiros tempos da humanidade se exprimia na sua pureza absoluta, na ausência de contaminações e poluições ${ }^{21}$.

Para ser mais precisa, há sinais corruptíveis, juntamente com outros, muito menos numerosos, cuja degeneração para Delsarte parece ser impraticável. Inatacáveis são os movimentos involuntários, enquanto o perigo da alteração come- 
ça onde se pode inserir a razão entre impulso interior e sua manifestação exterior, faculdade demasiadamente humana, não submissa à autoridade de Artifex. Entre a dinâmica não controlada, Delsarte coloca o levantar-se dos ombros: não, é claro, aquele que todos podem fazer como um exercício regular de ginástica, mas a ação, muito reduzida e, talvez, diferente na forma, causada pelo músculo do diafragma quando se é atingido por uma intensa emoção.

O que foi dito até agora envolve implicitamente que, como tentei demonstrar quinze anos atrás, qualquer interpretação da teoria artística de Delsarte como uma teoria positivista ou dele como um profeta do realismo (ideia que foi muito frequentemente apoiada) é totalmente incorreta, como é comprovado, claramente, em seus vários escritos tais como Positivisme dans l'art, em que Delsarte diz que no momento em que a arte se tornou "um gabinete de naturalista [...], ela se dessecou, se mumificou 22 ", assumiu o aspecto de "uma relíquia destinada aos antiquários [...], um ossário de onde escapa um odor de morte e diante do qual se sente o frio do sepulcro ${ }^{23}$ " (D. C. 1. OS 36b. 22bis, c. $5 r$; [Porte, 1992, p. 244]; D. C. 8 . 147. 5, c. $1 v)^{24}$.

A leitura filorrealista é, certamente, derivada de uma interpretação errônea de um dado: que Delsarte passou quarenta anos a observar os fenômenos e a obter assim um vocabulário fonético e gestual, definindo o significado íntimo de cada termo do mesmo (o polegar afastado da palma da mão indicaria vitalidade, um volume de voz alta juntamente com um tom alto indicaria raiva etc.). Tal dicionário deveria servir ao ator para compor a partitura fonético-gestual do personagem que lhe foi confiado, a qual tinha, como finalidade, expressar quanto, na sua opinião, estava escondido por trás das palavras do texto dramatúrgico de sua relevância. Aparentemente, então, estamos diante de uma concepção realista da arte atoral.

Mas os termos do vocabulário de Delsarte querem ser puros; Delsarte, assim, não pretende transcrever no mesmo qualquer gesto observado no cotidiano, mas escolher aquelas posições e aqueles movimentos do corpo que acredita ser o sigilo da perfeita linguagem primordial. Deixo de explicar como ele acredita que pode distinguir os sinais genuínos dos 
artificiais (tarefa pouco fácil, uma vez que se trata de uma das passagens menos clara do seu pensamento); o fato é que ele está convencido de que o dicionário feito por ele contenha a linguagem adâmica: nada a ver com a linguagem da vida cotidiana. Se o léxico selecionado - como dito anteriormente - deveria servir ao ator para compor a sequência de movimentos e de inflexões vocais do personagem a interpretar, no palco deveria ser representada uma tranche de Éden, e não uma tranche de vie, de acordo com as regras realistas. Delsarte escreve:

\begin{abstract}
A arte não é, como tem-se o hábito de dizer, a imitação da natureza; ela é a representação idealizada dela. Ela é a relação sintética das belezas esparsas da natureza com um modelo superior e definido. A arte é, em seguida e, sobretudo, a tendência da alma degradada em direção de sua pureza primitiva ou de seu esplendor final. A arte, numa só palavra, é a busca do modelo eterno ${ }^{25}$.
\end{abstract}

Quero encerrar com uma reflexão. Anos atrás eu formulei uma hipótese. Eu escrevi, mais ou menos, que depois de ter criado a partitura fonético-gestual do personagem, o ator deveria reproduzi-la friamente durante os ensaios por um número de vezes tão alto de poder fluir sem pensar. Uma vez que o ator tivesse dominado a mesma, ele teria experimentado de verdade os sentimentos do seu personagem para aquele mecanismo bem conhecido por Stanislavski (e pelo Stanislavski utilizado para criar o método habitualmente definido como ações físicas), segundo o qual não apenas a alma produz o gesto, mas também o gesto excita a alma. Ideia, esta última, presente, ainda que embrionariamente, já na Hamburgische Dramaturgie de Lessing e, depois de Delsarte, em William Archer e outros autores ${ }^{26}$.

Nesse contexto encontra-se uma articulação que adiciona uma problemática ainda não completamente resolvida, no que me concerne. Faz tempo que se questiona se Delsarte ensinou exercícios físicos para seus alunos ou se essa prática pedagógica pertence a Steele MacKaye, Genevieve Stebbins e ao delsartismo americano. Mais precisamente, se deve questionar se Delsarte teria inventado um training corporal para o ator, uma série de exercícios a serem realizados em uma fase 
anterior daquela destinada à preparação de um personagem, e se, portanto, o vocabulário gestual identificado ao longo dos anos não seria apenas para ser aplicado na construção de uma figura do drama, mas, mesmo antes disso, em uma espécie de educação física preparatória.

A questão surge já no final do século XIX, quando a filha de Delsarte, Marie Géraldy, em 1892, durante uma viagem para os Estados Unidos, teria afirmado que a ginástica praticada na América e difundida como uma invenção de seu pai não seria encontrada de maneira alguma no método de treinamento por ele concebido. " $\mathrm{M}{ }^{\mathrm{me}}$ Géraldy veio ao nosso país para contar-nos o significado do nome de Delsarte. Delsarte nunca ensinou ginástica. Sua vida inteira foi dedicada ao estudo das leis que governam a expressão" (Woodward, 1893, p. 561) ${ }^{27}$.

A declaração atribuída a Marie Géraldy pode ser interpretada de duas formas, ambas relacionadas com o método pedagógico delsartiano: como o repúdio de qualquer prática física antes de ser ensaiada um papel ou pelo menos uma situação expressiva como, a título exemplificativo, a súbita aparição de um objeto muito desejado; ou como o repúdio da atividade física específica - aquela definida como ginástica, seguida de algum adjetivo - exercida pelos seguidores do delsartismo.

Eu procurei entre os manuscritos de Delsarte e entre as anotações feitas pelos alunos diretamente das suas aulas, ou seja, entre os textos mais confiáveis (e imediatamente se admite que as únicas lições especializadas, reservadas aos discípulos destinados à carreira de atores ou cantores dos quais permanece registro escrito, parecem ser aquelas de Steele MacKaye, o que obviamente pode ser uma lacuna importante). Bem, eu não consegui identificar registros que possam demonstrar a existência de um treinamento desenhado pelo mestre, a fim de tornar mais ágil ou mais disponível o corpo do aspirante a ator ou cantor para realizar os gestos solicitados pelos papéis que depois os seriam dados. O exame dos vários manuscritos de Delsarte e das anotações de seus discípulos não levou a encontrar declarações que afirmem a existência de exercícios de decomposing, para usar o termo empregado pelos delsartistas americanos. Certamente temos desenhos e 
tabelas de mãos, de cabeças e de pernas, mas nada assegura que eles foram usados como memória visual para realizar exercícios de decomposição e não como ilustração de diferentes possibilidades corporais e dos seus significados. Em outras palavras, as tabelas podem ser esquemas construídos para mostrar os significados das posições representadas, e não o esquema com base no qual se executam exercícios úteis para desenvolver a agilidade através dos movimentos de articulação de cada parte do corpo.

Ao ler a tipologia de manuscritos mais críveis, descobrese também a presença de descrições de sequências motoras que representam o sentido submerso em uma ou mais frases, não necessariamente diálogos retirados de um texto dramatúrgico. Trata-se de relações sobre a partitura gestual justa, obtida através da observação da realidade exterior e da identificação dos traços arquetípicos presentes nele. Embora nunca se tenha dito, até onde eu saiba, que a execução das partituras ilustradas devem ser postas em prática para fins de treinamento, há pouca dúvida sobre o fato de que estas sequências sejam propostas publicamente pelos alunos e pelo próprio Delsarte em ocasião das aulas demonstrativas abertas para um público não necessariamente especializado, como aprendemos de quem, como Angélique Arnaud, a elas participou e as descreveu (Arnaud, 1882, p. 93-106). O que nos faz supor que nas aulas particulares os alunos as experimentassem e que, portanto, a elaboração e a execução dessas partituras constituíssem uma modalidade de exercitação.

Com base nas informações até aqui oferecidas é muito razoável especular, portanto, que as tabelas de posições e de movimentos do corpo desenvolvidas por Delsarte não sejam desenhadas como pro memoria para um training preliminar destinado apenas para a aquisição de uma agilidade física, ou seja, para uma espécie de ginástica precedente de cada opção expressiva, mas sim como amostra demonstrativa que, uma vez transposta para a materialidade concreta do corpo, deveria ser aplicada diretamente a uma situação específica (por exemplo, o fato de uma pessoa que espera uma outra com ânsia) ou a um determinado personagem dramático. 
Podemos alargar a base de investigação apoiando-nos em algum volume assinado pelos alunos de Delsarte após a morte do mestre, trabalhos que, porém, não têm o mesmo grau de credibilidade dos textos do autor ou escritos por quem transcreveu as suas palavras no momento em que as mesmas foram pronunciadas.

Nem Arnaud e tampouco Thomas Étienne Hamel afirmam explicitamente que no método delsartiano fosse pedido aos alunos para realizar exercícios práticos e que, portanto, houvesse um momento formativo distinto da exercitação para interpretar um personagem. Que Hamel, por exemplo, se prolonga sobre as formas na qual a mão se pode apresentar (Hamel, 1906, p. 159-169), não significa necessariamente que a descrição da sequência de posições corresponda a um exercício concretamente executado pelo aspirante a ator. Mais úteis são Giraudet e Delaumosne. Ambos dizem para não fazer nada mais do que apresentar o ensinamento delsartiano e dentro do relatório do primeiro autor são oferecidos Exercices pour les principaux types d'opposition (Giraudet, 1895, p. 102-103) e Exercices de souplesse du bras (Giraudet, 1895, p. 116-117); se trata de atividades físicas abstratas, a serem feitas para adquirir flexibilidade articular. Delaumosne intitula um capítulo como Série de gestes pour exercices e, em seguida, acrescenta o seguinte subtítulo: Série de gestes appliquée aux sentiments le plus souvent exprimés par l'orateur, seguido pela descrição da mímica, que indica "interpellation", "remerciement affectueux et cérémonieux", "surprise et assurance" etc. Cada gesto descrito é escandido em três, quatro, cinco, seis tempos; trata-se, portanto, de exercícios compostos por várias fases, que o aspirante a ator deve fazer como treinamento em um momento diferente e anterior aos ensaios.

Portanto, se em Giraudet encontramos formas de adestramento projetadas para tornar mais elástica e maleável a máquina anatômica sem comprometer o âmbito expressivo, segundo Delaumosne seria contemplada, sim, no sistema pedagógico delsartiano, uma forma de treinamento, mas desde o início orientada de forma expressiva, visando a aquisição de um domínio da retórica do gesto. 
As indicações de Delaumosne resultam muito semelhantes ao que me parece poder concluir a partir do exame dos escritos mais confiáveis. Giraudet, no entanto, sustenta uma tese em que os documentos principais parecem silenciar. É verdade que é previsto no método delsartiano de formação do ator ou do cantor também um training corpóreo de caráter gímnico como aquele exposto por Giraudet?

O que é certo é que um treinamento voltado para tornar a máquina anatômica mais ágil e flexível existe em MacKaye e na Stebbins e que também é previsto por artistas nãoamericanos do início do século XX, inspirados em Delsarte (penso, por exemplo, em Mejerchol'd, que teria lido e teria sido influenciado pelos escritos de Sergej Volkonskij sobre Delsarte) $)^{28}$.

De uma forma ou de outra, e admitido que na verdade pelo menos o treino mais orientado no sentido expressivo pertença à prática pedagógica delsartiana, o training desenvolvido pelo mestre francês poderia implicar um fim de absoluta importância. $\mathrm{O}$ ator poderia de fato ter a tarefa não só de aplicar uma partitura fonético-gestual a um personagem, mas, antes disso ainda, de aprender os movimentos arquetípicos e, então, de reconstruir, através de um treinamento ad hoc, novos hábitos corpóreos em relação aos velhos, considerados estereotipados e falsos, em oposição aos novos hábitos considerados ideais e verdadeiros. De reconstruir novos hábitos - quero dizer - a serem adquiridos em fase de formação, para sempre, para qualquer contexto (teatral e cotidiano). Tratar-se-ia, então, de uma prática semelhante a dos atores muito mais próximos cronologicamente a nós e comportaria uma visão antropológica de trabalho ainda mais marcada que aquela até aqui lançada como hipótese.

A ideia de elaborar um training a fim de modificar os hábitos corpóreos para vestir-se de novos é expressa por MacKaye de forma explícita, mas em um texto provavelmente de 1886, portanto, que remonta a vários anos após a morte de Delsarte, por isso facilmente não se trata de reevocar o pensamento do mestre, mas de uma ideia concebida por MacKaye: 
Movimentos decompositores são aqueles que têm por objetivo aumentar a faculdade de relaxamento dos músculos, ou que completam a entrega do corpo pelo Ser, que tende a romper mais rapidamente e destruir velhos hábitos de movimento, e a desenvolver com mais perfeição aquela flexibilidade na organização muscular, que a torna extremamente suscetível à influência de todas as gradações emocionais, e modelando-a de modo mais completo para realizar todas as mais sutis funções da expressão [...]. Quanto mais arraigado for o velho hábito, mais restrito e rígido o músculo se torna, e mais difícil é de cultivar a sua flexibilidade ${ }^{29}$ (D. C. 6. 76. 1, p. 26$27)^{30}$.

Ao reler os manuscritos de Delsarte e dos transcritores de suas palestras, só uma tese me relembra, até certo ponto, as ideias defendidas por MacKaye, e é aquela, já apresentada aqui, sobre os tipos habituais; ideia que é relatada, desta vez, por um aluno que está anotando uma palestra proferida pelo mestre em 1855:

Existem três dimensões no homem: há a dimensão constitucional (dimensão formal, a dimensão que se tem ao nascer), e em seguida há as dimensões passageiras que eu chamarei de passionais. E há, também, uma terceira dimensão de modelos: são as dimensões que eu defino como habituais, ou seja, essas dimensões passionais frequentemente reproduzidas no homem e que modificam seu ser miológico a ponto de modificar seus ossos, formando nele uma constituição particular. É por isso que se diz que o hábito é uma segunda natureza. Em verdade, a repetição de um movimento molda o ser material, o ser físico, criando um modelo que não é de nascença, e que eu chamo de habitual (D. C. 12. 86, p. 132; [Porte, 1992, p. 129] $)^{31}$.

O passo - por inciso, uma ulterior confirmação da ideia delsartiana segundo a qual o indivíduo no decorrer da sua história ou da história do gênero humano adquiriu hábitos distantes do arquétipo - refere-se à esfera do real e não da arte. Não é dito (mas nem sequer é excluído), portanto, que tal mecanismo, para o qual a repetição de um dado movimento cria uma nova natureza, seja transportado no campo da formação atoral e aplicado a fim de alcançar, pelo aprendiz de ator, um hábito fiel ao arquétipo ao invés do modelo humano-tão- 
humano gerado a partir da Queda. Certamente, no entanto, com base em importantes declarações de Delsarte apenas propostas, MacKaye e, depois dele, alguns artistas da vanguarda histórica, chegaram a inventar um training para levar o ator a incarnar uma nova natureza, caracterizada, de acordo com o caso, por uma maior beleza, por uma mais compacta unitariedade, por uma transparência mais consistente no que diz respeito à esfera interior. 


\section{Notas}

${ }^{1}$ Os manuscritos mencionados são preservados na Delsarte Collection da Hill Memorial Library de Baton Rouge, na Louisiana (abreviatura: D. C.). São colocados em caixas numeradas, em um folder numerado e são frequentemente identificados também por um número de item. Por exemplo, um manuscrito pode ser armazenado na caixa 1 , folder 24 , item 6 . A referência no texto do nosso artigo, então, será: D. C. 1. 24. 6, seguido, quando necessário, pelo número do cartão (c.) ou da página (p.). Quando a parte citada de um manuscrito é encontrada em PORTE, Alain. François Delsarte: une anthologie. Paris: IPMC, 1992, a indicamos a seguir, entre colchetes. Por exemplo: D. C. 1. 24. 6, c. 2; [Porte, 1992, p. 61].

D. C. 12. 86 - Manuscrito intitulado Cours de Mons. Delsarte, preservado em D. C. box 12, folder 86. Este texto é uma transcrição de uma série de palestras realizadas por Delsarte. Segundo referido por Alain Porte, que teve acesso a outra transcrição da mesma conferência em posse da família Delsarte e realizada por um tal Degard, o ano na qual essas lições aconteceram seria 1855 .

${ }^{2}$ Ver nota 1.

${ }^{3}$ D. C. 11.40 - Caderno manuscrito intitulado Esthétique Appliquée. Cours de F. Delsarte. Exposition en neuf leçons de l'Art de l'Orateur, du Peintre et du Musicien, preservado em D. C. box 11, folder 40. O caderno contém anotações, tiradas da Alphonse Pagès que se referem a uma série de conferências realizadas por Delsarte em 1859. Há notas e correções de Delsarte.

${ }^{4}$ No original em francês: "L'homme porte en lui le caractère de trois types distincts: le type stable ou constitutionnel, ou essentiel, c'est le type de naissance; le type habituel ou acquis contracté sous l'influence des mouvements; le type passionnel ou fugitif produit par les passions modifiant temporairement les formes. Les trois types nous donnent organiquement deux sources d'études: les formes et les mouvements. Les formes nous révèlent la valeur intime de l'homme, les dispositions qu'il apporte en naissant. Les mouvements nous révèlent ses habitudes, son état spécial, en un mot sa valeur relationnelle. [...] La forme nous apprend ce que l'homme peut être mais elle ne nous apprend pas ce qu'il est. C'est la seconde source de notre étude, le geste, qui nous apprend à connaître l'état actuel de sa valeur" (D. C. 1. 24. 5 , c. $5 r-v$; ver nota 5 ).

${ }^{5}$ D. C. 1.24. 5 - Texto manuscrito o qual incipit è Les êtres ont reçu trois modes de révélation, preservado em D. C. box 1, folder 24, item 5. A grafia não parece de Delsarte. Provavelmente trata-se de anotações feitas por um aluno nos cursos de Delsarte. O manuscrito deveria remontar aos anos 1850 .

${ }^{6}$ No original em francês: "La forme nous apprend ce que l'homme peut être mais elle ne nous apprend pas ce qu'il est".

${ }^{7}$ No original em francês: "C'est la seconde source de notre étude, le geste, qui nous apprend à connaître l'état actuel de sa valeur'.

${ }^{8}$ Declarações semelhantes também são encontradas em outros manuscritos. Por exemplo: "As dimensões são formais ou constitucionais, passionais, habituais. Nós nascemos com um modelo 
formal incessantemente modificado pelas paixões. Quando essas modificações se multiplicam, o modelo primordial sofre uma modificação habitual". No original em francês: "Les types sont formels ou constitutionnels, passionnels, habituels. Nous naissons avec un type formel incessamment modifié par les passions. Quand ces modifications se sont multipliées, le type primordial prend une modification habituelle" (D. C. 11. 40, p. 69; ver nota 3).

9 Johann Jacob Engel é citado no D. C., 12. 84, c. 63r. Também é mencionado em Giraudet (1895, p. 8). (D. C. 12.84 - Caderno manuscrito de notas feitas por Steele MacKaye em Paris sobre as lições de Delsarte nos anos 1869-1870, mantidas em D. C. box 12, folder 84).

${ }^{10}$ Giraudet cita La Théorie de la démarche como um texto inspirado nos ensinamentos de Delsarte, indicação obviamente incorreta, uma vez que é publicado em 1833 (e não em 1847 como escreveu Giraudet), quando Delsarte tinha apenas 22 anos (Giraudet, 1895, p. 9).

${ }^{11}$ No original em francês: "L'humanité est comme estropiée, la beauté n'existe que par fragments, elle n'est nulle part sur cette terre. Les types ne se trouvent pas, ils sont dans l'intellect, ils ne sont pas dans la nature. La beauté n'est nulle part, il faut par conséquent qu'elle soit constituée par l'artiste par un travail synthétique” (D. C. 12. 86, p. 18; ver nota 1).

${ }^{12}$ No original em francês: "Examinons de nouveau l'homme dans ce qui constitue essentiellement son être. Je veux parler des trois puissances pour lesquelles Dieu l'a fait à son image [...]. Ce qui me frappe d'étonnement, c'est la dissonance où elles se trouvent. C'est l'état d'inégalité où elles sont tombées" (D. C. 1. 26b. 10, c. 8; ver nota 13; [Porte, 1992, p. 240]).

${ }^{13}$ D. C. 1. 26b. 10 - Esthétique. Conférence à l'école de médecine, em D. C. box 1, folder 26b, item 10. Este é um manuscrito de notas de Delsarte preparatórias para uma palestra realizada por ele, segundo Porte, em 1867 (PORTE, Alain. François Delsarte: une anthologie. Paris: IPMC, 1992, p. 233).

${ }^{14}$ No original em francês: "L'homme porte en lui les traces indéniables d'une grandeur foudroyée, car il n'a pu sortir ainsi mutilé des mains de son créateur et Dieu n'a pas pu mutiler son œuvre en estropiant ainsi sa ressemblance [...]. L'homme a-t-il pu sortir ainsi estropié des mains de son créateur? Dieu n'a-t-il pu suffire à son œuvre de prédilection ou bien a-t-il voulu dès le berceau de la création mutiler sa ressemblance? S'il en était ainsi, Dieu ne serait pas seulement un maladroit ouvrier, mais il serait encore le plus dur, le plus injuste et le plus cruel des êtres" (D. C. 1. 26b. 10, cc. 8-9; ver nota 13; [Porte, 1992, p. 240]).

${ }^{15}$ No original em francês: "Tout cela n'est pas admissible. Cependant l'homme porte les caractères indéniables d'une grandeur foudroyée" (D. C. 1. 26b. 10, cc. 8-9; ver nota 13; [Porte, 1992, p. 240]).

${ }^{16}$ No original em francês: "Quand un homme vous dit, sous une forme interjective "J'aime, je souffre, je suis charmé, etc.", n'en croyez rien si son épaule est demeurée dans une attitude normale [...]. N'en croyez rien, il ment! Son épaule infirme sa parole. Cette forme négative a trahi sa pensée" (D. C. 1. OS 36c. 2, c. 18 Chapitre VI; ver nota 17; [Porte, 1992, p. 85]).

${ }^{17}$ D. C. 1. OS 36c. 2 - O manuscrito de François Delsarte, Mes Épisodes Révélateurs, ou Histoire d'une Idée appelée à constituer la base de la Science et de l'Art, encontra-se em D. C. e remonta ao período de 1869-1871. Este texto está preservado em box 1, folder OS 36 c, 
item 2. Somente os primeiros dois parágrafos do texto encontram-se nas primeiras duas folhas da box 1, folder 26 b, item 7 .

${ }^{18}$ No original em francês: "N'en croyez rien, quelle que soit d'ailleurs l'expression qu'affecte son visage” (D. C. 1. OS 36c. 2, p. 18 Chapitre VI; ver nota 17; [Porte, 1992, p. 85]).

${ }^{19}$ No original em francês: "Si quelqu'un veut exprimer de la surprise et que cette surprise ne soit pas précédée d'une titillation, vous pouvez être assurés que la surprise est simulée. Si m'attendant à la visite d'une personne je feins de l'émotion à sa vue, vous pouvez dire 'C'est faux parce qu'il n'y a pas eu de titillation dans le regard"” (D. C. 12. 86, p. 174; ver nota 1).

${ }^{20}$ Ver nota 1.

${ }^{21}$ Que a ideia da decadência do homem como fruto da história tenha raízes neoplatônicas em Delsarte é explicado por ele mesmo. Ver, por exemplo, D. C. 12. 86, p. 104-106; ver nota 1.

${ }^{22}$ No original em francês: "un cabinet de naturaliste [...], s'est desséchée, momifiée”.

${ }^{23}$ No original em francês: "une relique à l'usage des antiquaires [...], un ossuaire étiqueté d'où s'échappe une odeur de mort et devant lequel on sent le froid du sépulcre" (D. C. 1. OS 36b. 22 bis, c. $5 r$; ver nota 24; [Porte, 1992, p. 244]; D. C. 8. 147. 5, c. 1v; ver nota 24).

${ }^{24}$ D. C. 1. OS 36b. 22bis - Manuscrito Positivisme dans l'Art. Conférence, preservado em D. C. box 1, folder OS 36b, item 22 bis. O manuscrito contém notas de Delsarte para uma conferência, talvez incluída em uma série de palestras realizadas em torno de 1865. Em duas folhas manuscritas, o qual incipit é Temple de l'art (D. C. box 8, folder 147, item 5) encontramse anotações quase idênticas, constatações que sugerem tratar-se de folhas relacionadas com a mesma conferência. Talvez se trate de duas redações diferentes do mesmo texto.

${ }^{25}$ A citação é extraída da primeira das dez palestras realizadas por Delsarte em 1855 (Cours de Mons. Delsarte), palestra ausente na cópia preservada em D. C. 12.86 (ver nota 1), mas presente em uma outra transcrição de posse da família Delsarte, da qual Alain Porte me doou gentilmente sua transcrição. No original em francês: "L'art n'est pas comme l'on dit l'imitation de la nature; il en est la représentation idéalisée. C'est le rapport synthétique des beautés éparses de la nature à un type supérieur et defini. L'art est ensuite et surtout la tendance de l'âme déchue vers sa pureté primitive ou sa splendeur finale. L'art, en un mot, est la recherche du type éternel".

${ }^{26}$ A ideia de que o gesto possa influenciar a alma está presente em certos escritos do século XVIII e XIX: não apenas em Lessing, que nas páginas datadas de 08 de maio de 1767 da Hamburgische Dramaturgie, analisa a questão, mas também em autores posteriores a Delsarte assinalados por Anne-Marie Drouin, como Charles Darwin e William Archer (Drouin, 1995, p. 133). Anne-Marie Drouin acrescentou que o efeito da alma colocada em movimento pelo gesto pode ser definido como "[...] efeito Campanella em memória de uma anedota contada sobre o autor da Cidade do sol por Burke, e retomada por Dugald Stewart, depois por Albert Lemoine e William James. Campanella, ao que se diz, quando desejava saber o que se passava na cabeça de uma outra pessoa, reproduzia da melhor maneira que podia sua atitude e sua fisionomia atuais, concentrando ao mesmo tempo a atenção nas suas próprias emoções" (Drouin, 1995, p. 
133). No original em francês: "[...] effet Campanella en souvenir d'une anecdote racontée sur l'auteur de la Cité du Soleil par Burke, et reprise par Dugald Stewart, puis par Albert Lemoine et William James. Campanella, dit-on, lorsqu'il désirait savoir ce qui se passait dans l'esprit d'une autre personne, contrefaisait de son mieux son attitude et sa physionomie actuelles en concentrant, en même temps, son attention sur ses propres émotions" (Drouin, 1995, p. 133).

${ }^{27}$ No original em inglês: " $\mathrm{M}^{\mathrm{me}}$ Géraldy came to our country to tell us what the name of Delsarte means. Delsarte never taught gymnastics. His whole life was devoted to the study of the laws that govern expression".

${ }^{28}$ Interessante, neste contexto, a intervenção de Fausto Malcovati (Delsarte in Russia all'inizio del Novecento. I saggi di Volkonskij) na conferência I movimenti dell'anima. François Delsarte fra teatro e danza, realizada em Pádua e Verona em 13 e 14 de Dezembro de 2011. Os Anais estão sendo publicados.

${ }^{29}$ No original em inglês: "Decomposing motions are those whose aim is to increase the faculty of relaxation in the muscles, or that complete surrender of the body by the Being, which tends to most speedily break up, and destroy old habits of motion, and to most perfectly develop that flexibility in the muscular organisation, which renders it most susceptible to the influence of all shades of emotion, and fits it most completely to perform all the subtlest functions of expression [...]. The more deeply imbedded the old habit is, the more constricted and stiff the muscle becomes, and the more difficult it is to cultivate its flexibility" (D. C. 6. 76. 1, p. 2627; ver nota 30 ).

${ }^{30}$ D. C. 6. 76. 1 - Transcrito de Steele MacKaye intitulado Harmonic Gymnastics. Simple, and complex expressions, and stage business, preservado em D. C. box 6, folder 76, item 1. Provavelmente remonta a 1886.

${ }^{31}$ No original em francês: "Il y a trois sortes de types dans l'homme: il y a des types constitutionnels (des types formels, le type qu'on apporte en naissant), et puis il y a des types fugitifs que j'appellerai passionnels. Et puis il y a une troisième sorte de types: ce sont les types que j'appelle habituels, c'est-à-dire que ces types passionnels très fréquemment reproduits chez un homme modifient son être myologique et arrivent même à modifier ses os, de sorte qu'il se forme en lui une constitution particulière. De là vient qu'on dit que l'habitude est une seconde nature. En effet, l'habitude d'un mouvement façonne l'être matériel, l'être physique, de sorte qu'elle crée un type qui n'est pas de naissance, que j'appelle habituel" (D. C. 12. 86, p. 132; ver nota 1; [Porte, 1992, p. 129]). 


\section{Referências}

ARNAUD, Angélique. François del Sarte: ses découvertes en esthétique, sa science, sa méthode. Paris: Delagrave, 1882.

DELSARTE, François. Méthode Philosophique du Chant. Paris: à compte d'auteur, 1833. In: PORTE, Alain. François Delsarte: une anthologie. Paris: IPMC, 1992. P. 149-153.

DROUIN, Anne-Marie. Sémiologie du Geste, Jeu Théâtral et Simulation: l'artifice au service de l'explication du vivant. Ludus Vitalis, Iztapalapa-Mexico City, Universidad Autonóma Metropolitana, v. III, n. 4, p. 127-155, 1995.

GIRAUDET, Alfred. Mimique Physionomie et Gestes. Méthode pratique D’après le système de F. Del Sarte [sic] pour servir à l'expression des sentiments. Paris: Librairies-imprimeries Réunies, 1895.

HAMEL, Thomas Étienne. Cours d'Éloquence Parlée d'après Delsarte. Québec: Imprimerie de la Compagnie de “L'Événement”, 1906.

PORTE, Alain. François Delsarte: une anthologie. Paris: IPMC, 1992.

RANDI, Elena. Il Magistero Perduto di Delsarte. Dalla Parigi romantica alla modern dance. Padova: Esedra, 1996.

TRAITÉ de la Raison (1870). Transcrição de um manuscrito encontrado por Porte nos arquivos particulares da família Delsarte. Cf. PORTE, Alain. François Delsarte: une anthologie. Paris: IPMC, 1992. P. 247-257. A escritura do documento original não é de Delsarte, mas seu conteúdo, provavelmente, sim.

WOODWARD, Adèle M. Delsarte's Daughter In America. In: Delsarte System of Oratory. New York: Edgar S. Werner, 1893². P. 561-565.

Elena Randi é doutora em Teoria e História da representação dramática pela Università Cattolica del S. Cuore di Milano. É professora na Università di Padova, na Itália, onde ensina História do Teatro e do Espetáculo. Entre seus livros estão: François Delsarte: le leggi del teatro, Editora Bulzoni, de 1993; Il magistero perduto di Delsarte, Editora Esedra, de 1996; Percorsi della drammaturgia romantica, Editora UTET, de 2006; I primordi della regia. Nei cantieri teatrali di Hugo, Vigny, Dumas, Editora Pagina, de 2009; e V. Hugo, Angelo, tyran de Padoue, Edição Crítica, Editora Le Lettere, de 2012.

E-mail: elena.randi@unipd.it

Traduzido do original em italiano por Débora Geremia.

Recebido em 01 de fevereiro de 2012 Aprovado em 20 de maio de 2012 